\title{
What makes multicomponent school-based health promotion interventions work? A qualitative study nested in the SEHER trial in Bihar, India.
}

Sachin Shinde ( $\square$ discovery.sachin@gmail.com )

Harvard University T H Chan School of Public Health

Prachi Khandeparkar

Sangath

Bernadette Pereira

Kendriya Vidyalaya Sangathan

\section{Amit Sharma}

Sangath

\section{David A Ross}

London School of Hygiene and Tropical Medicine Department of Population Health

Helen A Weiss

London School of Hygiene and Tropical Medicine Department of Population Health

\section{George Patton}

University of Melbourne

Vikram Patel

Harvard Medical School Department of Global Health and Social Medicine and Sangath

\section{Research article}

Keywords: School health promotion, Health Promoting Schools, adolescents, lay counsellor, qualitative study, cluster randomized controlled trial, India

Posted Date: July 14th, 2020

DOI: https://doi.org/10.21203/rs.3.rs-41144/v1

License: (c) (i) This work is licensed under a Creative Commons Attribution 4.0 International License. Read Full License 


\section{Abstract \\ Background}

A cluster-randomized controlled trial in secondary schools in Bihar, India, reported the effectiveness of a multi-component, school health promotion intervention (SEHER) when delivered by lay counsellors ("SEHER Mitra" (SM); meaning "friend" in the local language), but not when delivered by a teacher ("Teacher as SEHER Mitra" (TSM)) compared with the government-run Adolescence Education Program (AEP). This nested qualitative study explored what key factors determined the effectiveness of the intervention and the difference in effectiveness by the delivery agent.

\section{Methods}

We purposively selected 12 intervention schools ( 6 each from the two intervention arms) based on the size of school. In these schools, we conducted semi-structured interviews with 12 principals, 12 AEP teachers, 12 other teachers, and 11 students who participated in SEHER counselling services. We conducted focus group discussions with girl students $(n=14)$, boy students $(n=12)$ SMs $(n=2)$, TSMs ( $=2)$, and supervisors $(n=1)$. Data analysis followed a framework approach to thematic analysis.

\section{Results}

Three overarching themes were identified - i.e. stakeholders' understanding of SEHER; SEHER intervention planning and implementation, and other issues in the implementation process. All the stakeholders from both the arms strongly believed that the SEHER program was important in imparting health knowledge and life skills to secondary school students. The following factors facilitated the successful implementation of SEHER in SM-arm schools: a shared understanding of the SEHER program by the whole school community, influential school-level leadership, engagement of, and collaboration with, all stakeholders including students in program activities, the trust of the school community in the SMs, full-time availability of SMs for program activities, and prompt actions on students' concerns by the SMs. Barriers to effective implementation of SEHER in TSM-arm schools included: lack of communication and poor relationship-building between the TSMs, principals and other teachers, TSMs' perceptions that they were overburdened with academic and non-academic responsibilities, students' lack of clarity about the TSM's role, concerns about confidentiality, inaction on students' concerns, and lack of support from other teachers and the department of education.

\section{Conclusions}

The embedded qualitative study identified important facilitators and barriers to the effective implementation of the intervention when delivered by two different delivery agents. 


\title{
Trial registration:
}

\author{
www.clinicaltrials.gov/ NCT02484014
}

\section{Background}

Schools are critically important platforms for health promotion in adolescents, and school-based health interventions can improve health, psychosocial, and educational outcomes [1-3]. A whole-school, multicomponent approach appears to have the greatest impact compared with single-risk targeted discrete interventions [1, 2, 4, 5]. However, most studies are from high-resource settings with well-developed school systems, and few have contributed to an understanding of how these effects can be achieved and what are the key components of such programs $[6,7]$.

The SEHER project (Strengthening the Evidence base on scHool-based intErventions for pRomoting adolescent health) developed and evaluated the effectiveness of a multi-component school-based health promotion intervention to improve school climate and adolescent health [8]. We tested the intervention in two delivery formats, one delivered by lay counsellors (called SEHER Mitra (SM); Mitra meaning 'friend' in the local language) and the other by teachers (called Teacher-as SEHER Mitra; TSM), in government-run secondary schools in Nalanda district of Bihar, India. Comparison schools received the Adolescence Education Program (AEP), a classroom-delivered life-skills curriculum, which was conducted in all schools in all arms. Full details of the intervention and the evaluation have been reported elsewhere [810]. Box 1 provides an overview of the SEHER interventions and trial.

Box 1: Overview of the SEHER Trial 
Aim: To evaluate the effectiveness and cost-effectiveness of SEHER, a whole-school multi-component health promotion intervention, led by lay counsellors or teachers in government-run secondary schools to promote school climate and thereby improve adolescent health outcomes

Study setting and duration: 74 government-run secondary schools in Nalanda district of Bihar, India; 25 schools in the SEHER Mitra (SM) arm; 24 schools in the teacher as SEHER Mitra (TSM) arm and 25 schools in the control arm (April 2015-February 2017)

Design: Cluster randomized controlled trial using repeated cross-section surveys; Three-point assessment-at baseline, 8-months after baseline and 17-months after baseline

Inclusion criteria: All the students studying in grade 9 (13-15years) and present on the day of assessment were eligible to participate in the study.

Total study participants: 13,035 at the baseline; 14,414 at 8-month follow-up and 15,232 at 17-month follow-up

Intervention: SEHER, a multi-component whole-school intervention was designed within the HPS framework. The intervention's conceptual framework emphasizes the importance of a positive school climate i.e. supportive relationships between school community members, a sense of belonging to the school, a participative school environment, and student commitment to academic values. The intervention identifies four priority areas for action: promoting social skills among adolescents; engaging the school community in school-level decision-making processes; providing access to factual knowledge about health and risk behaviours to the school community; and enhancing problem-solving skills among adolescents. The intervention strategies were organized at three levels: whole school, group and individual levels. The whole-school level activities included setting a School Health Promotion Committee, conducting regular awareness generation activities during a school assembly, organizing competitions, providing a platform to students to raise their concerns complaints and suggestions anonymously through a suggestion box, running a monthly wall-magazine and developing and implementing healthy school policies. The group-level activities included forming and running classroom-based peer groups to address students' concerns; a workshop for students on effective learning techniques and a workshop for teachers on effective disciplinary practices in the school. The individual-level component included providing problem-solving-based counselling to students who self-referred or were referred by teachers for health complaints, social difficulties and academic difficulties. This intervention was delivered through a trained lay counsellor or trained teacher.

Selection and training of SM/TSMs: The TSMs were nominated by the school principals, had a minimum of 5 years teaching experience in secondary schools, had 15 or more years of service remaining, and not teaching the Adolescence Education Program curriculum (control intervention). The SMs were members of the local community, were above 18 years of age, had completed at least a bachelor's degree, and fluent in the local language (Hindi). The TSMs and SMs underwent a week-long separate training, with an identical curriculum. This was followed by in-service training through separate monthly group meetings for TSMs and SMs. Eight supervisors provided support and supervision to a combination of SMs and TSMs through three planned visits per month.

Comparison intervention: The Adolescence Education Program was delivered in all three arms of the study. A trained teacher from each school ran classroom-based sessions on the process of growing up, establishing positive and responsible relationships, gender and sexuality, prevention of HIV and other sexually transmitted infections, and substance use. These topics are delivered during 16 hours of sessions per academic year.

Primary outcome: school climate measured through 28-items Beyond Blue School Climate Questionnaire

Secondary outcomes: Depressive symptoms, frequency of bullying, attitude towards gender norms, knowledge of reproductive and sexual health and violence (perpetration and victimization)

We previously reported strong effects of the SEHER intervention on school climate, violence and bullying, depression and attitude towards gender norms after one academic year of exposure, and dose-response effects after two years, in the SM arm of the trial. On the other hand, there was no evidence of an intervention effect on any outcome either after one or two years of intervention in the TSM arm [9-10]. 
We prospectively nested a qualitative study within the trial to explore the processes of, and challenges in, the delivery of the two interventions (SM and TSM) and to examine the intervention components and school-level factors that were critical to the effectiveness or lack of effectiveness of the two interventions. This study was conducted before the unblinding of the trial findings and was thus not informed by the observation of the differential effectiveness of the two delivery formats.

\section{Methods}

Sample: The SEHER trial was conducted between June 2015 and January 2017 with three assessments - i.e. the baseline survey in June 2015; an 8-months follow-up survey and 17- month follow-up survey post-baseline. The qualitative study was conducted between January and February 2016, before commencing the 8-months follow-up survey. Twelve intervention schools, six from each intervention arm were randomly selected based on school size, defined as: i) small school $=101-300$ students $(n=2$ schools per intervention arm); ii) medium school $=301-600$ students ( $n=2$ schools per intervention arm), and iii) large school $=601$ or more students ( $n=2$ schools per intervention arm).

Data collection: Four data collection strategies were employed.

\section{Focus group discussions (FGDs) with students}

Two FGDs were conducted in each school (one each with boys and girls in co-educational schools). Students studying in grade 9 (the sample selected for the quantitative outcome assessments for the trial) and members of the peer groups (see Box 1) were invited to participate in the FGD.

\section{FGDs with the delivery agents}

Twenty-four TSMs and 25 SMs were divided into two subgroups each and an FGD was conducted with each subgroup $(n=4)$. One focus group discussion was conducted with the eight supervisors.

\section{Semi-structured interviews with school staff}

In each school, the principal, AEP teacher, and one randomly selected teacher were interviewed.

\section{Semi-structured interviews with students}

In each school, one semi-structured interview was conducted with a purposively selected student who had used the counselling services from the SM/TSM during the academic year.

The interview and FGD guides were developed for this study (Additional files 1,2, 3 \& 4) and each of them broadly covered the following areas: understanding of the intervention; roles of various school community members in the intervention activities; experience of participating in the implementation of intervention activities in the school; usefulness of the intervention activities; and facilitators and barriers to implementation of intervention activities. All interviews and FGDs were conducted in the local language (i.e., Hindi). On average, the interviews lasted 60 minutes and FGDs for 90 minutes. All the 
interviews and group discussions were audio-taped, transcribed verbatim, and then translated into English. Subsequently, the field notes written by the interviewers were attached to the transcripts.

Analyses: The "framework method" integrating both deductive and inductive approaches, guided the data

coding and analysis [11-12]. The initial coding framework was based upon a-priori themes covered in the interviews and group discussions. We randomly selected and examined five transcripts to add new emerging themes and re-organize the initial framework. Two independent coders coded the data using NVivo software (version 6) and met to compare and reconcile coding. After coding, common themes were organized into a matrix and salient themes were identified for each arm.

Ethical considerations: Ethical approval was obtained from the Institutional Review Boards of Sangath, India, and the London School of Hygiene and Tropical Medicine, United Kingdom. Written informed consent was obtained from all the adult participants. We sought opt-out parental consent and participant assent for participants who were under 18 years of age. Both the Institutional Review Board approved the use of opt-out parental consent for the participants who were under 18 years of age.

\section{Results}

The semi-structured interviews and FGDs were conducted in 12 schools including one boys only, three girls only, and eight co-educational schools. Altogether we interviewed 45 participants including 10 principals, 12 AEP teachers, 12 other teachers, and 12 students who had used counselling services (6 boys and 6 girls). We conducted 24 FGDs with students (14 with girls and 10 with boys), which involved 248 students; 2 FGDs each with SMs and TSMs, and one with supervisors.

Framework analysis helped in organizing the enablers and barriers to SEHER implementation under three overarching themes: stakeholders' understanding of SEHER; SEHER intervention planning and implementation, and other issues in the implementation process. All the themes and sub-themes are discussed below.

\section{Theme 1: Understanding of SEHER}

Importance and relevance of SEHER in education

The most common enabler reported under the theme of understanding of the SEHER program by the interviewees (principals and teachers) from the SM-led schools, was the importance and relevance of SEHER in the education of students. These interviewees reported that schools are an ideal location to impart behavioural skills because most of the students do not have access to health and life skills education at home or elsewhere in their community. Participants said that educating young men and women on health and hygiene, emotional health and gender issues and rights, was a must given the poor health literacy, low marital age among women, and the high prevalence of violence and sexual abuse against women in India. 
"SEHER provides important life-skills education to the students. In rural areas, young people don't have supportive parents, especially girls who live in a strict environment...for them, the SEHER program provides an opportunity to access health education and life-skills." [Teacher, SM school]

Conversely, the most common barrier observed in the TSM-led schools was the perceived lack of importance and relevance of SEHER in students' education. The interviewed principals and teachers mentioned that providing education on health and life skills was not one of the duties of a teacher and it was burdensome implementing health programs in schools as they compromise teaching time.

"All the health programs in schools are shouldered by teachers... be it distribution of iron-folic acid tablets, AEP or SEHER... our primary job is teaching; teachers are not in the school to implement health programs." [Principal, TSM arm school]

\section{Understanding of SEHER's intervention conceptualization}

Another enabler related to the understanding of SEHER was the importance of a shared understanding of the program concepts by all the school community as a prerequisite for successful implementation. On the other hand, the interviewees from TSM-led schools mentioned that the lack of a shared understanding of the program concepts within the school community was an important barrier to successful planning and implementation of the SEHER TSM intervention.

The SM/TSMs were supposed to brief and engage with principals, teachers, and students in their respective schools about the intervention in the early stages of the planning and implementation process. However, most of the interviewees in the TSM-led schools reported that no orientation had been provided to them at the planning stage by the TSMs.

Interviewees from the SM-led schools reported that the monthly meetings held with the school staff by the SM and supervisor and the activities organized during daily assembly helped in creating awareness of the program. They described how the intervention was modeled on the pillars of building a positive school climate and designed to improve the capacity of the school to address the health needs of the students. They also mentioned that the students and teachers contributed to a participatory and democratic process of building a positive school climate. The interviewees also referred to the conceptual framework of the intervention and reported that the intervention aimed to provide factual information to students on health and well-being as well as impart life-skills such as decision making and problemsolving.

"We were told by the SM that the main objectives of SEHER are to improve social and problem-solving skills among adolescents, make the students aware of various physical and mental health issues and involve them in school activities. We were also briefed that all this can be done by improving the overall physical and social environment in the school." [Female Principal, SM school]

Conversely, the principals and teachers from TSM-led schools reported not receiving any written information on SEHER from the TSM or visiting supervisor. This contributed to the lack of understanding 
of the objectives among stakeholders in these schools and created several challenges in the planning and implementation of the intervention.

"We were not briefed enough about SEHER. We should have been given complete information at the initiation of the program. I also feel that 2-3 copies of the SEHER manual, some handouts, brochures, etc. should have been kept in the school so that teachers could read and get familiar with the key concepts and activities of SEHER." [Teacher, TSM school]

Students from both intervention arms were able to describe the SEHER program components and events. Students mentioned that SEHER aimed to provide information on a range of topics through assembly sessions, wall-magazines, and classroom interactions and to help them build skills such as decision making, problem-solving, communication, and interpersonal skills, anger management, time management, creative thinking, and public speaking.

"Through wall-magazine and assembly sessions, the SM sir provides us information on various topics like health, gender and violence, mental health, and substance use. He talks with us about some important skills like how to control anger; how to improve concentration and memorization; and how to make a decision and solve problems. This program helps us in building skills and I like it. The wallmagazine provides an opportunity to develop our creative skills like drawing, painting, and writing." [Female student, SM school)

\section{Theme 2: SEHER intervention planning and implementation}

Three major sub-themes emerged as important facilitators or barriers to the successful planning and implementation of SEHER: roles and responsibilities of key stakeholders; collaboration and engagement; and governance and management.

\section{Roles and responsibilities of key stakeholders}

Two sub-themes surfaced when participants described the roles and responsibilities of key stakeholders: principal as a leader and SM and TSM as a facilitator of the intervention activities.

Principal as a leader. Since school principals have authority for the day-to-day operation of schools, their involvement in the program activities were perceived by the SMs and supervisors as essential to the acceptance and roll-out of SEHER. The principal's acceptance, commitment, support, and ability to articulate the importance of the program activities and motivate and inspire other teachers resulted in the smooth implementation of program activities. The principal's involvement examples included forming and organizing meetings of the School Health Promotion Committee, advising the SM and supervisor on solving students' issues, creating a consensual plan of action to solve students' concerns, and utilizing the school funds for purchasing school-level assets and equipment.

"...support by the school principal was very important. He was very much interested in this initiative and because of his interest, other teachers were also compelled to support SEHER activities. His strong 
leadership also translated into obtaining financial support for school development activities... everything can be done if the principal pays attention to the issues in the school." [Female SM]

In contrast, the principals in the TSM schools reported that the TSMs preferred not to consult them in planning activities and reached out only when the students demanded changes in school infrastructure. Many TSMs felt that the principal nominated them to be the Teacher as SEHER Mitra to burden them with additional responsibilities. It was clear that the dynamics and lack of communication between the TSMs and principals led to poor relationship building and collaboration between key stakeholders (i.e., among TSM, principal, and teachers), which resulted in a poor buy-in and an impaired understanding of the SEHER intervention among school staff.

"When the program was planned, nobody consulted with us. At the school level, it was important to facilitate the distribution of different roles and build capacity among teachers however, no joint meeting was organized where principals and teachers were clarified about their role." [Principal, TSM school]

SM/TSM as a facilitator of SEHER: The SM/TSMs were expected to act as the catalyst and facilitator of the building of a positive school climate and addressing student concerns through intervention activities. The SMs and TSMs were frequently reminded by the SEHER supervisors at the monthly meetings that their abilities to listen, assess, enable, and build trusting relationships were core skills that would lay the foundation for facilitating the planning, implementation, and evaluation of this collaborative approach.

Principals and teachers mentioned that the fact that the SM was able to work full-time to drive SEHER program activities was an enabler of successful implementation in their respective schools. They appreciated the SM's enthusiastic nature and passion for working with students. They also said that, under the guidance of experienced supervisors, the SMs organized numerous activities throughout the year, which helped in establishing a supportive environment for students. Principals also acknowledged the additional duties shared by the SMs such as preparing students for competitions, assisting the school staff during examinations, and assuming the responsibilities of a librarian or arts and craft teacher.

"Dialogue between teachers and students has increased since SEHER has started in our school. There are many opportunities for the students to interact with the teachers... every month there is some celebration or competition, which has improved the interaction between students and teachers." [Female teacher, SM school]

Students perceived the SM as someone who was 'friendly, approachable, and deeply interested in addressing their concerns. Students mentioned having faith in the SM who could help them in solving problems while maintaining confidentiality. Students also valued their experiences of engaging with the SM in fun activities, which were not part of their regular studies but helped them to gain knowledge and skills.

"I was going through a personal problem. My parents wanted to stop my education and get me married. I was disturbed due to this fact and couldn't concentrate on anything. I did not know what to do so I went 
to SM sir. He patiently listened to my problem and assured me that nothing of that sort would happen. He asked me whether I would be okay if the principal talked to my parents, which I thought was an okay thing to do. My parents were called to the school. Our principal and SM sir discussed this issue with my father a couple of times and my parents agreed to continue my education and not to think about my marriage before I complete grade 12 education". [Female student, SM school]

The supervisors and SMs reported about the significant efforts invested by the supervisors and project team in integrating the SM into the school and gaining the acceptance and support of the school community. These efforts included organizing regular meetings with the staff, involving teachers in planning and implementing competitions, leading the daily school assembly, and assisting the principal in non-academic duties.

"In the initial year, the response from the teachers and staff was lackluster; in some incidences, they created hurdles. However, as time passed, the SMs started helping out teachers in their duties, attending classes when teachers were not able to do so; started helping out in the day-to-day activities of the school, for example, organizing daily assembly, helping teachers during exams, preparing and escorting students for inter-school competitions, assisting in administrative tasks, and so on. This all helped in accepting the SMs as a member of the school." [Male Supervisor]

On the other hand, the TSMs mentioned that not having dedicated time and resources to deliver the program hindered the program implementation in their schools. They could not fully perform the role of the SEHER Mitra due to ancillary academic (e.g., deputation for evaluation of answer sheets, cluster meetings, etc.), non-academic (e.g., deputation for elections), and administrative duties (e.g., preparation and submission of monthly attendance reports of students) given to them. They also raised concerns about the program creating additional work for them without providing any monetary incentives.

"We are overburdened with responsibilities such as clerical work, preparing documents for the distribution of all the student voucher schemes, etc. We are also sent to election duty, examination duty, cluster meetings, etc. On top of that, teachers implement programs like AEP and SEHER. We are not given any incentive or recognition for doing this extra work." [Male TSM]

The TSMs also mentioned that attempts made by them to undertake a coordination role and to encourage teachers to implement activities were met with some resistance.

"In this school, students have flooded the speak-out box complaining that teachers do not attend the classes regularly and the school schedule is not followed-up. I organized a meeting with the principal and teachers to discuss these issues. Instead of suggesting changes, many teachers accused the students of not being interested in learning. Teachers were reluctant to change their practices." [Female TSM]

Students mentioned that they were confused about the dual role of the TSM, who was a regular teacher in the classroom and performed as the SEHER Mitra during program activities. Many students expressed concerns about sharing their issues with the TSM as they thought the TSM would not respect 
confidentiality and share their issues with other teachers; a few students also reported incidents where confidentiality had been breached. Many female students expressed their hesitation to seek help from a male TSM. Students also complained about the unavailability of the TSM in the school due to other engagements.

"I could not share my problem with him [the TSM]. I felt uneasy to discuss something personal with him. I wondered what he would make out of it. I was not sure if he would keep it only with him or would share it with other teachers. Nevertheless, I approached him for help. He listened to me carefully but as we were sitting in the teacher's room, there was a lot of disturbance. Constantly someone was entering the room, I was not comfortable during those meetings." [Female student, TSM school]

Some students also mentioned that during the peer group meetings, the TSM did not listen to their suggestions and took the decisions on major concerns independently.

"We wanted to access the books in the library during school hours. We suggested to him that the peer group members in each classroom could take the responsibility of distributing them at the beginning of the class and collecting them at the end of the class. He did not agree with it and said it was not possible." [Male student, TSM school]

\section{Collaboration and engagement}

Collaboration and networking within the school: In the SM schools, the interviewees acknowledged that the democratic and participatory approach used by the SM to facilitate the intervention planning and implementation was the key contributor to successful implementation. They mentioned that the mapping exercise and meetings with staff and peer-groups were crucial strategies in understanding the needs of the students and generating and implementing the action plan.

“We) were always asked to share our opinions. For example, if there was a function to be organized on someday, she (the SM) would ask how we want to celebrate it, or if there was a common complaint in the speak-out box, she would ask us the ways to solve it. Our opinion was also taken into consideration while making a decision." [Male student, SM school]

Teachers from the SM schools appreciated that it was for the school to analyze its reality and find solutions to the school-level problems. Consequently, when teachers consulted and involved in decisionmaking, the resulting SEHER activities were viewed more favourably.

"We were all asked if there was anything that we wanted to include in SEHER activities for the second year. [This was] an opportunity to give our ideas to improve the program; this was very new. This has never happened in any other program." [Female Teacher, SM school]

In contrast, the lack of internal collaboration and networking efforts from the TSMs was a barrier to the implementation of intervention activities in the TSM schools. The TSMs reported that the principal and teachers were not keen to incorporate program activities in the daily schedule of the school due to 
accumulating academic and non-academic pressures. On the other hand, principals and teachers from the TSM schools mentioned that the TSM never sought their advice to implement program activities.

"Most of the teachers were reluctant to participate in the program activities... there is a culture in Bihar, if someone is doing something good then instead of supporting, people prefer to create obstacles... I am also a teacher so not blaming other teachers...the system is broken; it requires a fix. The education department needs to invest in training teachers to change their attitude and build a supportive culture." [Female TSM]

Student engagement. Interviewees from the SM-led schools mentioned that students were engaged in program activities due to the relevance and multiple benefits to them (i.e., personal, social, and academic) as well as the participation in the decision-making process. Student engagement, mainly through making posters, flyers and banners, presenting skits, and participation in meetings, pivoted on a perception that the program was both fun to take part in and addressed a perceived knowledge and skills deficit.

"SEHER has been a great fun... competitions, classroom debates, or role-plays in the assembly... there was so much to learn for all the students. I got a chance to try my skills in public speaking, writing, and painting through various competitions. The SM provided us study tips and counselling was available to those students who had personal problems." [Female student, SM school]

There was an overwhelming consensus among students from the SM-led schools that the success of SEHER was due to the initiative actively involving and empowering students. Students mentioned that prompt action on students' issues increased their faith in the SM and participation in intervention activities. They cited that the program was successful at bringing students and teachers together to have stimulating conversations on students' concerns, which they would normally not associate with classroom teaching.

Contrary to this, students from TSM arm schools felt that the lack of student inclusion in the decisionmaking process hampered program implementation. They voiced that their schoolmates were nervous to participate in activities such as designing the monthly wall-magazine, competitions, whole-school assembly activities, and peer club meetings. They also mentioned that most students stopped participating in SEHER activities because the school did not take any action on the complaints shared by them through the suggestion box.

"... we were told that students could share their concerns through the suggestion box, so we kept complaining about dirty toilets; non-availability of fans; and not having enough benches in the schools. No action was taken by school...nobody asked about our suggestions." [Male FGD participant, TSM school]

Parental involvement. The interviewees from the SM-led schools considered the efforts to involve parents in the School Health Promotion Committee (SHPC) were beneficial because it allowed the formation of a nucleus to initiate the process of change in the school. For example, in one SM school, the issue of open 
defecation around the school boundary and on the school ground was discussed in one of the meetings and hence, the parents took the lead and talked with the local leaders and community members to resolve this issue. Parents' involvement was also regarded as important because it opened up a dialogue between the school management and parents regarding discipline issues in schools.

"In every meeting, he [the SM] would ask whether parents have any ideas to put forward, what would they like to discuss, or any particular activity they would like to organize or follow-up on. He would talk to all the committee members individually, and that helped to bring more parents to the school." [Female teacher, SM school]

The lack of parental representation and engagement in the SHPC was a commonly reported barrier across the TSM-led schools. The TSMs believed that there is a lack of a culture of collective participation in all spheres of society and schools are no exception to it. The school teachers complained that parents visit the schools only when there is a distribution of vouchers or free goods.

\section{Governance and management}

The SEHER intervention makes a few recommendations aimed at providing a coherent and sustainable infrastructure for intervention implementation. Thus, at an individual school level, each school was expected to establish the SHPC comprising representatives from the entire school community. The objective of this committee was to drive the program and ensure that it was rolled out in an effective and relevant way. It was thought that the SHPC would be more likely to take ownership of the program, thereby promoting program relevancy and sustainability. In SM-led schools, the principals followed the development and implementation of the SHPC. These committees understood their role in reviewing the priorities identified by the students and discussed and acted on the possible ways to address these priorities. However, in TSM-led schools, the SHPCs never functioned to their fullest potential due to resistance from school management from the outset. Most of the school principals expressed concerns, that assuming responsibility for SEHER governance and management would create additional workload pressures for staff. These concerns were legitimate given the additional academic and non-academic responsibilities assigned to the teachers. However, this reluctance to embrace the establishment of a SEHER support infrastructure also reflects the lack of clarity around the understanding of the program and the absence of a sense of ownership by the school management and shared agreement on roles and responsibilities in the TSM schools. Furthermore, the program tended to be seen by members of the school community as an add-on to school services rather than an overall framework and ethos embedded within existing school structures.

"Every school was supposed to set up a Committee through which the school would decide the priorities for the school. This committee would come up with solutions for the students' concerns. However, in most of the TSM schools, this committee was formed as a formality. Parents were reluctant to visit schools and principals were not enthusiastic enough. This resulted in poor execution of this component and enough pressure was not built to implement activities which could have changed the school's ethos." [Male Supervisor] 


\section{Other issues in the implementation process}

Readiness of schools

A key consideration in the exploration and planning stage of implementation was an assessment of the 'readiness' of the setting. It was evident from a range of interviewee responses that many broader factors had posed an obstacle to successful SEHER implementation in the TSM-led schools. For example, principals reported that without time and resources including human, financial and material, it is futile to implement a program. Principals also mentioned the budgetary restrictions by the Department of Education (DoE) to use the school development fund for improving the school infrastructure was an obstacle. The interviewees from the TSM arm schools also mentioned that the DoE is implementing multiple programs when the schools are understaffed. The TSMs mentioned that complementary actions were required between the program staff of the AEP, Going-to-School program, and SEHER, to generate a holistic plan to address the actual needs of the students, which was more likely to succeed in the context of Bihar.

"The government does not want to take responsibility for long-term initiatives... the education system in Bihar is chaotic... multiple programs are being implemented in schools through teachers but nobody in the government thinks of one program...this is a challenge of the bureaucracy." [Male Principal, TSM school]

Fidelity issues

The process evaluation of SEHER during the implementation period indicated that the coverage of intervention activities was better in SM-led schools relative to TSM-led schools. This highlighted the importance of the Standard Operating Procedures developed to guide the implementation of each component of the intervention being followed. Some TSM-led schools tended to implement their version of intervention activities. Thus, the program was initially based on the individual views of how the program would be delivered rather than the evidence-based health-promoting school practices which underpinned it.

"The guideline on peer-group formation mentions that an election method should be followed to select peer-group members. Instead, in some schools, the TSM selected the members. Similarly, the manual describes the steps to be followed to read and discuss the wall-magazine issues in a classroom setting, however, very few TSMs followed these guidelines."[Male SEHER supervisor]

Support from the Department of Education: Principals and TSMs perceived that the lack of Departmental monitoring, technical assistance and support for SEHER negatively affected its implementation. They complained that DoE officials never visited the schools to review the program activities, coordinate activities with other school-based programs, follow-up with the TSMs or recognize the additional responsibilities shouldered by the TSMs and teachers to implement the program. According to the principals, the involvement of the DoE is necessary to understand the challenges faced by the schools in 
bringing about change. However, there were no efforts from the DoE officials to reach out to the principals and understand the ground-level situation.

\section{Discussion}

This paper report findings of the qualitative investigation nested in the cluster randomized controlled trial evaluation of the SEHER multicomponent, school-wide health promotion intervention in secondary schools in Bihar, India, when delivered by two distinct delivery agents i.e., a lay counsellor (SM) or a teacher (TSM). The trial had reported that when the intervention was delivered by the lay counsellors (SM) was associated with significant improvements in school climate and adolescent health outcomes such as depression, bullying, violence and attitude towards gender norms when compared with the government-run Adolescent Education Program. There was no evidence of intervention effects when the intervention was delivered by trained teachers (TSM) in comparison to the government-run Adolescence Education Program.

The study offered an unbiased opportunity to specifically interrogate these divergent findings, in particular why teachers were not effective in delivering the same intervention as lay counsellors. This qualitative study contributes to understanding the different findings when the intervention was delivered by the two distinct agents (SM vs TSM). First, it is important to recognize that SEHER was a health promotion intervention, functioning in the existing school system, with its strengths and weaknesses. The leadership of the school principal was fundamental in leading and directing the intervention activities at school-level, by allocating resources and integrating the intervention into the school's daily schedule. However, engagement of the principal with this leadership role varied across schools and this had an important bearing on how the SEHER progressed in each school. The SMs accepted the leadership role of the principal and this, in turn, led the principals to accept the SMs and the SEHER intervention as a whole, whereas the frequently competitive dynamics between the TSMs and principals appeared to create confusion and conflicts amongst the school community in the TSM-arm schools. Also, most of the SMs were able to generate and cultivate the support of those teachers who believed in the value of the program and were willing to participate in program activities and this also aided in successful implementation in the SM-led schools. These facilitators are consistent with studies of the implementation of school health interventions [13-15]. For example, a process evaluation of the Mentally Healthy Schools program in Australia reported that if the principals and teachers are passionate about the program then that sets the tone positive and supports implementation. The global case studies of HPS documented that the ownership and participation of many principals and teachers are instrumental in moving from ideas on paper to actions in schools [16].

Second, most of the TSMs were enthusiastic about facilitating the program in the schools but felt that they were overburdened with non-academic and academic responsibilities, which limited their engagement in the program activities. In contrast, the SMs were additional, externally-funded staff and were viewed by many as a useful additional member of school staff who provided hands-on support to the school community. Students could easily approach the SMs due to their full-time availability for this 
role within the school. Indeed, one evaluation of a Healthy Schools program in the US documented that the provision of a health coordinator as an additional staff member was linked to an improved health education curriculum as well as greater improvements in the development, implementation, and sustainability of health-related policies [17].

Third, a key consideration in the exploration and planning stage of implementation was an assessment of the 'readiness' of the setting [18]. Not surprisingly, it was evident from interviewee responses that broader factors had posed an obstacle to successful SEHER implementation in the TSM-led schools. For example, most principals noted that budgetary restrictions as well as a lack of sufficient staff had impacted the ability and openness of schools to support intervention implementation. The lack of visible Department of Education support for SEHER resulted in limited staff engagement with intervention activities. Evidence suggests three general areas that affect the overall stage of readiness: strategic planning, preparation, and organizational readiness and functioning for the actual implementation process [19]. Evidence suggests that school readiness depends on several factors, such as the level of motivation among staff and the surrounding community, assessment of risks and anticipated outcomes, and the availability of resources and support [20-22].

Fourth, how school climate and adolescent health and well-being were identified and understood by the school community was an important contributory factor in the intervention implementation. A qualitative case study of a Canadian province-wide HPS initiative described that school health initiatives that are understood, supported, and perceived as consistent with the school culture by the school teachers and principals aid in successful implementation [23]. This gap in awareness and knowledge of programs among stakeholders has also been corroborated in past studies as barriers to sexual health and nutrition education and policy implementation within schools [24-25].

Fifth, student engagement in the program activities was better in the SM schools than the TSM schools. This is because, in the former, students were clear about the role of the SM, were comfortable in interacting with the SM and school staff, and participated in the decision-making processes. Students also valued prompt action or communication by the SMs regarding their concerns. In contrast to this, the lack of student participation in decision-making processes posed a barrier in TSM-led schools. The findings of this study also reinforce the recognition of the importance of constructive partnerships within the school community, and in particular, it highlights the importance of the relationship between students and teachers in terms of mutual reciprocity, participation in decision-making, trust, and confidentiality. These findings support the current literature [26-28] and build on it by identifying the key elements that initiate and sustain these partnerships, not only between school staff and students but also between school staff and the broader school community, such as parents.

Finally, it was identified that an effective governance and management structure is a key contributory factor in the successful engagement of, and collaboration with, stakeholders in any new initiative [26, 27]. For example, at an individual school level, each school was expected to establish its own Health Promotion School Committee comprising representatives from the entire school community to drive the 
SEHER intervention and ensure the program was rolled out in an effective and relevant way. However, the school-based committee, as set out in both the intervention guideline and the HPS literature [29], didn't function to its maximum in the TSM schools due to resistance from school staff or poor parental participation from the outset. Evidence also suggests that a clear structure of management and roles along with the structured involvement of the wider community in all stages of design, planning, and implementation may be key to the sustainability of HPS-related school improvements [21]. More specifically, the setting up of school-based HPS steering groups/committees provides a useful framework for schools in planning and designing the health-promoting policies, procedures, and activities $[20,30]$.

We acknowledge limitations within our study. First, due to time and resource constraints, we could not include the control arm schools in the qualitative study and hence, we are not in a position to describe causes of differences in the results between the two intervention arm schools (SM/TSM) and the control arm schools. Second, our findings and conclusions are subject to potential bias from our preconceptions and theoretical positions. We tried to minimize this bias by conducting the qualitative interviews and group discussions before the end-point survey and by including inductive coding of the narrative data.

\section{Conclusions}

Through nesting a qualitative study in the trial, we have been able to identify factors that influenced the implementation of the SEHER intervention within the SM and TSM arms of the trial. Thus, these findings provided important support to the quantitative findings by contextualizing the outcome findings. Our inclusion of multiple stakeholders in the qualitative study enabled us to triangulate the findings from different actors and to ensure that the findings applied to decision-making at the school level.

\section{Declarations}

\section{Ethics approval and consent to participate}

This study was approved by the Institutional Review Boards of Sangath, India, and the London School of Hygiene and Tropical Medicine, United Kingdom.

\section{Consent for publication}

Not applicable

\section{Availability of data and material}

The datasets generated and/or analyzed during the current study are not publicly available due to ethical restrictions related to protecting participants confidentially but are available from the corresponding author on reasonable request.

\section{Competing interests}


VP is supported by a Wellcome Trust Principal Research Fellowship in Clinical Science. VP is a co-founder of Librum, a consulting firm for mental health. GP is supported by a National Health \& Medical Research Council Senior Principal Research Fellowship. We declare no competing interests.

\section{Funding}

This study was funded by the John D and Catherine T MacArthur Foundation (Chicago, IL, USA) and the United Nations Population Fund, India Office. The funding source had no role in the design of this study and its execution, analyses, interpretation of the data, or decision to submit results.

\section{Authors' contributions}

SS, PK, GP, and VP designed the study. SS, PK, BP, and AS developed the study instruments and collected data. HW, DR, GP, and VP were involved in planning and supervised the work. SS, PK, BP, and AS transcribed and translated the audio-data and prepared it for analysis. SS, BP, and AS were involved in coding data. SS, PK, and BP performed the analysis and interpreted the analysis. HW, GP, DR, and VP reviewed the analysis and interpretation. SS drafted the manuscript and authors commented on and finalized the manuscript. All authors have read and approved the manuscript.

\section{Acknowledgments}

This study was a collaboration between Sangath, Goa-India; the Department of Education, Government of Bihar, India; and the London School of Hygiene and Tropical Medicine, United Kingdom. The authors would like to thank the entire intervention staff. We also thank all the students, teachers, and staff who participated in the study in Bihar.

\section{References}

1. Langford R, Bonell CP, Jones HE, Pouliou T, et al. The WHO Health Promoting School framework for improving the health and well-being of students and their academic achievement. Cochrane Database of Systematic Reviews. 2014; (4 Art. No. CD008958).

2. Shackleton N, Jamal F, Viner RM, Dickson K, et al. School-based interventions going beyond health education to promote adolescent health: systematic review of reviews. Journal of Adolescent Health. 2016; 58: 382-96.

3. Regan M, Fawzi W, Patel, V. Promoting global adolescent health: realizing the transformative potential of schools. Journal of Adolescent Health. 2020; in press.

4. Patton C, Sawyer S, Santelli JS, et al. (2016). Our future: a Lancet commission on adolescent health and wellbeing. Lancet. 2016; 387: 2423-78.

5. Hale DR, Fitzgerald-Yau N, Viner RM. A systematic review of effective interventions for reducing multiple health risk behaviours in adolescence. American Journal of Public Health. 2014;104: e-19e41. 
6. Gugglberger L, Inchley J. Phases of health promotion implementation into the Scottish school system. Health Promotion International. 2012; 29(2): 256-66.

7. Jamal F, Fletcher A, Harden A, Wells $H$, et al. The school environment and student health: a systematic review and meta-ethnography of qualitative research. BMC Public Health. 2013; 13: 798.

8. Shinde S, Pereira B, Khandeparkar P, Sharma A, et al. The development and pilot testing of a multicomponent health promotion intervention (SEHER) for secondary schools in Bihar, India. Global Health Action. 2017; 10: 1385284.

9. Shinde S, Weiss HA, Varghese B, Pereira B, et al. Promoting school climate and health outcomes with the SEHER multi-component secondary school intervention in Bihar, India: a cluster-randomised controlled trial. Lancet. 2018; 392: 2465-2477.

10. Shinde S, Weiss HA, Khandeparkar P, Pereira B, et al. A multi-component secondary school health promotion intervention and adolescent health: an extension of the SEHER cluster randomized controlled trial in Bihar, India. PLOS Medicine. 2020: 17(2): e1003021.

11. Miles M, Huberman A. Qualitative Data Analysis. An Expanded Sourcebook. 2nd edn. California: Sage Publications, 1994.

12. Braun, V, Clarke V. Successful qualitative research: A practical guide for beginners. London: Sage Publications, 2013.

13. Pearson $M$, Chilton $R$, Wyatt $K$, Abraham $C$, et al. Implementing health promotion programmes in schools: a realist systematic review of research and experience in the United Kingdom. Implementation Science. 2015;10.

14. Tancred T, Paparini S, Melendez-Torres GJ, Fletcher A, et al. Interventions integrating health and academic interventions to prevent substance use and violence: a systematic review and synthesis of process evaluations. Systematic Reviews. 2018; 7: 227.

15. Anwar-McHenry J, Donovan RJ, Nicholas A, Kerrigan S, et al. Implementing a Mentally Healthy Schools Framework based on the population-wide Act-Belong-Commit mental health promotion campaign. Health Education. 2016; 116 (6): 561-579.

16. Whitman CV, Aldinger C. Case studies in global school health promotion from research to practice. New York: Springer, 2009.

17. Turunen $\mathrm{H}$, Tossavainen $\mathrm{K}$, Jakonen $\mathrm{S}$, Vertio H. Did something change in health promotion practices? A three-year study of Finnish European Network of health-promoting schools, teachers and teaching. Theory and Practice.2006; 12(6): 675-692.

18. Weiner BJ. (2009). A theory of organizational readiness for change. Implementation Science. 2009; 4:67.

19. Simpson DD, Flynn PM. Moving innovations into treatment: A stage-based approach to program change. Journal of Substance Abuse \& Treat. 2007; 33 (2):111-120.

20. Lee A, St. Leger L, Moon A. Evaluating health promotion in schools: a case study of design, implementation and results from the Hong Kong Healthy Schools Award Scheme. International Journal of Health Promotion and Education. 2005; 12 (3-4): 123-129. 
21. Inchley J, Muldoon J, Currie C. Becoming a health-promoting school: Evaluating the process of effective implementation in Scotland. Health Promotion International. 2006; 22(1): 65-71.

22. Deschesnes MF, Trudeau F, Ke'be M. Factors influencing the adoption of a Health Promoting School approach in the province of Quebec, Canada. Health Education Research. 2010; 25 (3): 438-450.

23. Mclsaac JL, Hernandez KJ, Kirk SF, Curran JA. Interventions to Support System-level Implementation of Health Promoting Schools: A Scoping Review. International Journal of Environment Research and Public Health. 2016;13(2):200.

24. McCaughtry N, Martin J, Fahlman M, Shen B. Urban health educators' perspectives and practices regarding school nutrition education policies. Health Education Research. 2012; 27(1): 69-80.

25. Dickson E, Parshall M, Brindis C. Isolated voices: perspectives of teachers, school nurses, and administrators regarding implementation of sexual health education policy. Journal of School Health. 2019; 90 (2): 88-89.

26. Keshavarz N, Nutbeam D, Rowling L, Khavarpour F. Schools as social complex adaptive systems: a new way to understand the challenges of introducing the health promoting schools concept. Social Science and Medicine. 2010;70: 1467-74.

27. Murray-Harvey R, Slee, P. Supportive and stressful relationships with teachers, peers and family and their influence on students' social/emotional and academic experience of school. Australian Journal of Guidance \& Counselling. 2007; 17(2): 126-147.

28. Ma X. (2003). Sense of belonging to school: Can schools make a difference. The Journal of Educational Research. 2003; 96 (6): 340-349.

29. IUHPE,2009. Health promoting schools: Guidelines for promoting health in schools. iuhpe.org/index.html?page=50\&lang=en\#books_school.

30. Senior E. Becoming a health-promoting school: key components of planning. Global Health Promotion. 2012; 19 (1): 23-31.

\section{Tables}

Table 1: Details of interviews and focus group discussions

\begin{tabular}{|c|c|c|}
\hline & $\begin{array}{c}\mathrm{SM} \text { arm } \\
\mathrm{n}=6 \text { schools }\end{array}$ & $\begin{array}{c}\text { TSM arm } \\
\mathrm{n}=6 \text { schools }\end{array}$ \\
\hline \multicolumn{3}{|l|}{ Focus group discussions } \\
\hline Male students & 6 (56 boys) & 4 (47 boys) \\
\hline Female students & 6 (61 girls) & 8 (84 girls) \\
\hline Teacher-as SEHER Mitra & - & 2 (4 females \& 20 males $)$ \\
\hline SEHER Mitra & 2 (11 females \& 14 males $)$ & - \\
\hline SEHER supervisors & \multicolumn{2}{|c|}{1 (8 males) } \\
\hline \multicolumn{3}{|l|}{ Semi-structured interviews } \\
\hline Students who used the SEHER counselling services & 6 (3 boys \& 3 girls) & 6 (3 boys \& 3 girls) \\
\hline School principals & 5 ( 1 female \& 4 males $)$ & 5 (2 females \& 3 males) \\
\hline Adolescence Education Program teachers & 6 (5 females \& 1 male $)$ & 6 (4 females \& 2 males) \\
\hline Other teachers & 6 (2 females \&4 males) & 6 (2 females \& 4 males $)$ \\
\hline
\end{tabular}




\section{Additional Files}

1. Additional file S1: Guide for focus group discussions with students

2. Additional file S2: Guide for focus group discussions with delivery agents

3. Additional file S3: Guide for semi-structured interviews with school staff

4. Additional file S4: Guide for semi-structured interviews with school staff

\section{Supplementary Files}

This is a list of supplementary files associated with this preprint. Click to download.

- AdditionalFileS4.docx

- AdditionalFileS3.docx

- AdditionalFileS2.docx

- AdditionalFileS1.docx 